\title{
Qualitative assessment of information and decision support needs for managing menopausal symptoms after breast cancer
}

\author{
Lynda G. Balneaves ${ }^{1,2}$ • Dimitra Panagiotoglou ${ }^{3}$ - Alison S. A. Brazier ${ }^{3}$. \\ Leah K. Lambert ${ }^{3} \cdot$ Antony Porcino $^{4} \cdot$ Margaret Forbes $^{5} \cdot$ Cheri Van Patten $^{6}$. \\ Tracy L. O. Truant ${ }^{3} \cdot$ Dugald Seely $^{7} \cdot$ Dawn Stacey $^{8}$
}

Received: 24 January 2016 / Accepted: 30 May 2016/Published online: 8 June 2016

(C) The Author(s) 2016. This article is published with open access at Springerlink.com

\begin{abstract}
Purpose For breast cancer (BrCa) survivors, premature menopause can result from conventional cancer treatment. Due to limited treatment options, survivors often turn to complementary therapies (CTs), but struggle to make informed decisions. In this study, we identified BrCa survivors' $\mathrm{CT}$ and general information and decision-making needs related to menopausal symptoms.

Methods The needs assessment was informed by interpretive descriptive methodology. Focus groups with survivors $(n=22)$ and interviews with conventional $(n=12)$ and CT $(n=5)$ healthcare professionals (HCPs) were conducted at two Canadian urban cancer centers. Thematic, inductive analysis was conducted on the data.

Results Menopausal symptoms have significant negative impact on $\mathrm{BrCa}$ survivors. Close to $70 \%$ of the sample were
\end{abstract}

Lynda G. Balneaves

lynda.balneaves@utoronto.ca

1 Centre for Integrative Medicine, Leslie Dan Faculty of Pharmacy, 144 College St., Room 737, Toronto, ON M5S 3M2, Canada

2 Department of Psychiatry, Faculty of Medicine, University of Toronto, Toronto, Ontario, Canada

3 School of Nursing, University of British Columbia, Vancouver, British Columbia, Canada

4 Faculty of Medicine and Dentistry, University of Alberta, Edmonton, Alberta, Canada

5 Juravinski Cancer Centre, Hamilton, Ontario, Canada

6 British Columbia Cancer Agency, Vancouver, British Columbia, Canada

7 Ottawa Integrative Cancer Centre, Ottawa, Ontario, Canada

8 School of Nursing, University of Ottawa, Ottawa, Ontario, Canada currently using CTs, including mind-body therapies (45.5\%), natural health products (NHPs) and dietary therapies (31.8\%), and lifestyle interventions (36.4\%). However, BrCa survivors reported inadequate access to information on the safety and efficacy of CT options. Survivors also struggled in their efforts to discuss CT with HCPs, who had limited time and information to support women in their $\mathrm{CT}$ decisions. Concise and credible information about $\mathrm{CTs}$ was required by $\mathrm{BrCa}$ survivors to support them in making informed and safe decisions about using CTs for menopausal symptom management. Conclusions High quality research is needed on the efficacy and safety of CTs in managing menopausal symptoms following $\mathrm{BrCa}$ treatment. Decision support strategies, such as patient decision aids (DAs), may help synthesize and translate evidence on $\mathrm{CTs}$ and promote shared decision-making between BrCa survivors and HCPs about the role of CTs in coping with menopause following cancer treatment.

Keywords Breast cancer - Menopause $\cdot$ Information needs · Decision support $\cdot$ Complementary therapy

\section{Introduction}

At least $50 \%$ of women with breast cancer $(\mathrm{BrCa})$ will experience menopause as a consequence of cancer treatments [1-4]. The abrupt onset of menopause is particularly problematic for women with $\mathrm{BrCa}$ because they have not had an opportunity to acclimatize to waning levels of hormones in the same way that occurs for women in the general population [4]. The resulting symptoms of menopause can be extremely disruptive $[5,6]$ and significantly reduce $\mathrm{BrCa}$ survivors' quality of life $[2,7]$.

Treatment options for $\mathrm{BrCa}$ survivors experiencing menopausal symptoms are limited. Hormone replacement therapy 
(HRT) is typically avoided because of the potential risk of recurrence for hormone-sensitive cancer [8], despite recent research that suggests that it should be considered on a case-by-case basis [9]. Lifestyle changes, such as exercise and stress management, lack strong evidence of efficacy [10-12] and have been reported by $\mathrm{BrCa}$ survivors to have limited utility [13]. While some women may consider pharmaceutical options, such as antidepressants (e.g., venlafaxine), anti-seizures (e.g., gabapentin), or anti-hypertensives (e.g., clonidine), these medications can have significant and unwanted side effects.

Frustrated by the limited conventional treatment options available, $\mathrm{BrCa}$ survivors are motivated to search for alternatives, including such complementary therapies (CTs) as acupuncture or natural health products (NHPs) [14-16], with at least $25 \%$ of survivors using NHPs to address menopausal symptoms [17, 18]. BrCa survivors, however, have reported difficulty finding reliable, balanced information on CT options [19]. Information drawn from the Internet often lacks credibility and validity [20], is overwhelming in volume and rife with contradictory opinions $[13,21,22]$. Survivors are also frustrated by the lack of knowledge held by many conventional healthcare providers (HCPs) about CTs, despite the growing literature on the efficacy of CTs in managing menopausal symptoms both in the general $[23,24]$ and $\mathrm{BrCa}[25-27]$ populations. The limited time and resources available within conventional healthcare settings to support shared decisionmaking about $\mathrm{CTs}$ have posed further challenges for $\mathrm{BrCa}$ survivors considering CTs for menopausal symptom management [28].

These challenges highlight the need for decision support interventions, such as patient decision aids, that will support $\mathrm{BrCa}$ survivors to make informed decisions about CTs. Decision aids (DAs) are designed to increase patient involvement in the treatment decision-making process and reduce their decisional conflict by translating clinically relevant evidence into a patient-friendly format, while clarifying personal values relevant to the decision [2, 29-31]. DAs are not meant to "replace the human element in facilitating informed choice" [32] (p. 293), but rather aim to enhance dialogue about options between a patient and their HCP. Without such decision support, survivors are at risk for making uninformed decisions that can seriously impact their $\mathrm{BrCa}$ treatment and outcomes [33].

While DAs are available to inform menopausal $[30,34]$ and cancer treatment decisions [31], an aid specific for $\mathrm{BrCa}$ survivors considering CT options for menopausal symptom management has yet to be developed. The purpose of this study was to develop and evaluate the impact of a DA on $\mathrm{BrCa}$ survivors' decision-making behaviors and outcomes. However, the first step in developing a DA according to the International Patient Decision Aid Standards (IPDAS) [29] is to conduct a needs assessment to accurately capture the treatment options of interest and the information required by the target population.

\section{Aims of the study}

The aim of this needs assessment was to identify the CTs and related information to be included in a DA (called MyChoices $^{\mathrm{TM}}$ ) for $\mathrm{BrCa}$ survivors experiencing menopausal symptoms. The specific objectives were to (1) identify the most problematic menopausal symptoms experienced by $\mathrm{BrCa}$ survivors, (2) assess the $\mathrm{CT}$ and general information needs of $\mathrm{BrCa}$ survivors experiencing menopausal symptoms, and (3) understand what $\mathrm{BrCa}$ survivors were currently doing to manage menopausal symptoms.

\section{Methods}

The needs assessment was informed by qualitative descriptive methodology [35], which privileges the simple description of the phenomena under study.

\section{Sample and sampling}

Six focus groups were conducted with $\mathrm{BrCa}$ survivors recruited through the CAMEO Program ${ }^{1}$ [36], a survivorship clinic, and support groups located in two urban cancer centers in British Columbia and Ontario. A total of 22 women who met the eligibility criteria participated. Eligibility included the following: a diagnosis of stages I to IIIb $\mathrm{BrCa}$ in the past 5 years without recurrence, completion of primary cancer treatment, fluency in English, and considering CTs for menopausal symptom management. One woman unable to attend a focus group participated in a one-on-one interview.

Purposeful sampling with regard to timing of diagnosis, experience with CTs, and estrogen receptor status maximized sample size and diversity. Women who were diagnosed with estrogen receptor positive (ER+) $\mathrm{BrCa}$ were also purposefully sampled due to the controversy that exists regarding the potential role of select NHPs in stimulating a recurrence of ER+ $\mathrm{BrCa}[37,38]$.

Key informant interviews were conducted with a purposeful sample of 17 HCPs, including dietitians, pharmacists, nurses, general practitioners in oncology, and medical and radiation oncologists. Naturopathic doctors and natural health pharmacy personnel were also interviewed as they are often consulted by $\mathrm{BrCa}$ survivors about CT options $[39,40]$.

\footnotetext{
$1{ }^{*}$ CAMEO (Complementary Medicine Education and Outcomes) is a research program that studies the CT decision support needs of people living with cancer, their support persons, and HCPs, and develops programs and resources to help address those needs. CAMEO offers the latest $\mathrm{CT}$ research to the conventional cancer care setting through education courses and lectures, published documents, and individualized information and decision support consultations.
} 


\section{Data collection}

The focus groups were conducted by two trained facilitators using a structured interview guide (Table 1) informed by the Ottawa Health Decision Centre needs assessment workbook [41]. The focus groups encouraged $\mathrm{BrCa}$ survivors to discuss their menopausal symptoms and concerns, treatment options they had tried or were interested in, and the type of information they needed to make informed CT decisions. The focus groups and single interview were digitally recorded and transcribed verbatim. Survivors also completed a demographic form and the Menopausal Rating Scale (MRS) [42].

The key informants participated in 30-min interviews that focused on how they supported $\mathrm{BrCa}$ survivors in managing menopausal symptoms, including which therapies they recommended, how they addressed the use of conventional and complementary therapies, and what information they perceived to be important in making treatment decisions. The interviews were digitally recorded and transcribed verbatim.

\section{Data analysis}

Inductive thematic analysis [35] of the focus group and key informant interview data was conducted. The transcripts were read twice to develop a preliminary overview of key themes. An initial coding scheme was developed, which was used by two research team members (AB, LL) to separately code two transcripts to determine if the key concepts within the data were adequately captured. All transcripts were coded using the qualitative software, NVivo $^{\mathrm{TM}}$. Following coding, key concepts and themes in the data were further refined and compared across focus groups and participants. Memoing captured coding

Table 1 Survivor focus group interview guide

1. Understanding menopausal symptoms and concerns

a. What are the menopausal symptoms or concerns you are dealing with or anticipating struggling with?

2. Menopausal treatment options and information received

a. What treatments, including complementary therapies, have you tried or are considering?

b. What information have you been given about these options?

c. Where have you sought information?

d. Do you feel you need different information?

e. Has there been conflict in the information you have been given?

f. What has the decision been like for you?

3. Information preferences

a. What kind of information would you like about managing menopause?

b. How would you like this information presented to you? decisions, relationships among concepts and themes and questions to be posed in analyzing the data.

\section{Findings}

\section{Demographics}

The sample of women $(n=22)$ was diagnosed between 2008 and 2010, the majority $(n=13)$ with $\mathrm{ER}+$ stage II $\mathrm{BrCa}$ (Table 2). All women had an education level greater than high school, most self-identified as Caucasian $(63.6 \%)$, and the majority had annual household incomes greater than $\$ 70,000(63.6 \%)$.

Approximately two thirds of the HCPs had 10 years or more oncology experience, and just over half had some training or education related to CT $(52.9 \%)$ (Table 3$)$.

Table 2 Characteristics of the women with breast cancer $(n=22)$

\begin{tabular}{ll}
\hline Characteristic & Frequency $(\%)$ \\
\hline Age & \\
30-39 years & $2(9.1)$ \\
40-49 years & $9(40.9)$ \\
$50+$ years & $11(50.0)$ \\
Study site & \\
British Columbia & $17(77.2)$ \\
Ontario & $5(22.8)$ \\
Marital status & \\
Married/common law & $18(81.8)$ \\
Not married & $4(18.2)$ \\
Education & \\
Some college/college diploma & $11(50.0)$ \\
Bachelor degree & $5(22.7)$ \\
Graduate degree & $6(27.3)$ \\
Ethnicity/race & \\
Caucasian & $14(63.6)$ \\
Asian & $4(18.2)$ \\
South Asian & $1(4.5)$ \\
Missing & $3(13.6)$ \\
Household income (CDN\$) $\$ 30,000$ & $3(13.6)$ \\
\$30,000-\$70,000 & $5(22.7)$ \\
\$70,000 & $14(63.6)$ \\
Stage of BrCa & \\
Stage I & $3(13.6)$ \\
Stage II & $13(59.1)$ \\
Stage III & $5(22.7)$ \\
Missing & $1(4.5)$ \\
Receptor status & \\
Estrogen positive (ER+) & $16(72.7)$ \\
Progesterone positive (PR+) & $7(31.8)$ \\
HER2+ & $5(22.7)$ \\
Menopausal Rating Scale symptoms (moderate/severe & rating) \\
Hot flushes, sweating & $19(86.4)$ \\
Sexual problems & $19(86.4)$ \\
Sleep problems & $18(81.8)$ \\
Depressive mood & $16(72.7)$ \\
Physical and mental exhaustion & $16(72.7)$ \\
Mean total menopausal rating (s.d.) & $19.6(7.4)$ \\
\hline &
\end{tabular}




\section{Therapy choices}

The majority of women (68.2\%) were currently using a variety of CTs to manage their menopausal symptoms (Table 4). The most popular was mind-body therapies, which were used by $45.5 \%$ of the sample, followed by NHPs, which were utilized by close to $40 \%$ of the sample. Lifestyle interventions were also popular with $36.4 \%$ of the sample mentioning exercise or dietary changes. Just fewer than $20 \%$ of the women were using prescription or over-the-counter medications, such as anti-depressants, hormonal cream, and even HRT. Several women were hesitant to use pharmaceutical options due to concerns about side effects and the desire to avoid using additional medication following their cancer treatment.

\section{Perceptions about menopausal symptoms}

A key finding was that some women were not aware their symptoms were menopause, induced by their cancer treatment - and not a temporary, remediable effect. Although many of the women were informed that their menstrual cycles would end following treatment, they did not fully realize the implications and meaning of the associated physiological changes. The women were surprised by the sudden onset and intensity of their menopausal symptoms. A woman with stage III BrCa described her experience:

Table 3 Key informant demographics $(n=17)$

\begin{tabular}{ll}
\hline Characteristic & Frequency $(\%)$ \\
\hline Profession & \\
Medical oncologist & $2(11.8)$ \\
Radiation oncologist & $1(5.9)$ \\
General practitioner in oncology & $2(11.8)$ \\
Pharmacist & $3(17.6)$ \\
Dietician & $2(11.8)$ \\
Nurse & $1(5.9)$ \\
Nurse practitioner & $1(5.9)$ \\
Naturopathic doctor & $3(17.6)$ \\
Other & $2(11.8)$ \\
Study site & \\
British Columbia & $10(58.8)$ \\
Ontario & $7(41.2)$ \\
Years worked in oncology & \\
Less than 10 years & $6(35.3)$ \\
+10 years & $11(64.7)$ \\
Education in CT & \\
No & $8(47.1)$ \\
Yes & $9(52.9)$ \\
\hline
\end{tabular}

Table 4 Treatments currently used to manage menopausal symptoms $(n=22)$

\begin{tabular}{ll}
\hline Type of treatment & Frequency $(\%)$ \\
\hline Pharmaceutical options & $4(18.2)$ \\
Hormone replacement therapy & $1(4.5)$ \\
Hormone creams & $2(9.1)$ \\
Anti-depressants & $4(18.2)$ \\
Gabapentin & $1(4.5)$ \\
Vaginal moisturizer & $2(9.1)$ \\
Natural health products/food & $7(31.8)$ \\
Black cohosh & $3(13.6)$ \\
Vitamin E & $2(9.1)$ \\
Flaxseed & $5(22.7)$ \\
Soy & $1(4.5)$ \\
Passion flower & $1(4.5)$ \\
Homeopathic remedy & $1(4.5)$ \\
Traditional Chinese medicine & $1(4.5)$ \\
Reishi mushroom & $1(4.5)$ \\
Mind-body therapies & $10(45.5)$ \\
Lifestyle therapies & $8(36.4)$ \\
Other therapies & $2(9.1)$ \\
Acupuncture & $1(4.5)$ \\
Environmental changes (e.g., fan) & $1(4.5)$ \\
\hline
\end{tabular}

I didn't know I was having menopausal symptoms frankly... I didn't really know what to expect of chemo, and was just talking to a friend who is about 10 years older than me. I said, "Well, it's bearable, but I'm doing this and I'm doing that, you'll never believe this!" And she goes, "Oh, I've got all that." And it made me realize that what I was experiencing wasn't just solely because I was going through chemo...."

Both the survivors and HCPs indicated that the most bothersome symptom was hot flashes, throughout the day and night, which interrupted work and sleep, and caused significant social anxiety. The women struggled to hide the lengthy, uncomfortable flushing and associated sweating. A woman diagnosed over 5 years ago shared her experience:

I started chemo and it threw me into immediate menopause...I have extreme hot flashes. And during the summer I would have dozens every day and all night and to the point that I just wanted to cry. I was exhausted from just trying to get through one after another.

The reported impact of hot flashes was corroborated by survivors' responses to the MRS, with over $85 \%$ of women rating hot flashes and sweating as moderate to severe. Although other symptoms, such as sexual problems and sleep deprivation, were 
also reported to be extremely disruptive, many of these symptoms were directly attributed to hot flashes.

\section{Seeking treatment information}

Once women recognized their symptoms were menopauserelated and not a short-term side effect of their cancer treatment, many expressed uncertainty regarding which HCPs could best answer their questions: "Do I see my oncologist? Do I see my general practitioner (GP)?" Several expressed frustration with the scarcity of information about menopause management after BrCa and the lack of knowledge among HCPs. Some of the women who consulted their oncologist stated their menopausal symptoms were perceived as a relatively inconsequential outcome. A woman shared: “...their purpose [oncologists] was to keep you alive, but not give you that extra quality of life that you needed."

Many of the HCPs described their role in helping women make informed decisions about treating menopausal symptoms. They presented as having the knowledge and training necessary to understand the latest evidence and effectively translate that information without, as one naturopathic doctor framed it, "bamboozling" individuals. However, many felt ill equipped to recommend specific interventions due to the lack of clinical guidelines for menopausal symptom management following $\mathrm{BrCa}$ treatment. A medical oncologist explained:

There are many review articles on the topic so I would base my decision on the most recent literature review that I can find. We don't have guidelines that I have seen within the group on the management of menopausal symptoms.

Both the survivors and HCPs commented on the inconsistency among professionals regarding the management of menopause following BrCa. According to a pharmacist, "It's really going to be dependent on which physician they're seeing in the community." A lack of consistency was also perceived among health disciplines, which left women confused and frustrated. A naturopath shared:

Coming to see somebody like me and getting a different story than what they're getting from their oncologist and from their [general practitioner]...they [survivors] feel like they're getting three different stories and they don't know who to believe.

Acknowledging this confusion and lack of consistency, several HCPs confirmed that having a tool that summarized the evidence related to different menopausal treatment options, particularly CTs, would increase their ability to support women in the decision-making process. A general practitioner shared:
I think it's important for patients, but also for us because sometimes we don't know about these products [NHPs] and it would be nice if we had something that we could easily go to and say 'Okay, this is safe...don't worry about that one' and then you can [speak] with more confidence to the patient...

\section{Information needs related to menopausal symptom management}

Lacking decisional support from conventional HCPs, the women became resourceful in seeking information. They consulted friends and family members, other BrCa survivors, the Internet, as well as pamphlets, books, journals, and medical textbooks about the various treatment options available to manage menopausal symptoms. Foremost in women's minds was the safety of therapies in the context of a BrCa diagnosis. They had serious concerns that using a CT could interfere with their cancer treatment or promote the growth of their cancer. This concern overrode any possible benefit offered by a therapy, even when faced with highly disruptive menopausal symptoms. A pharmacist noted, "As soon as we really explain to them the distant possibility that you may actually do some harm for the $\mathrm{BrCa}$, they just back off. To them that's more frightful."

For the most part, however, it was the tentative and contradictory nature of the available information on the efficacy and safety of CTs that frustrated the women. A woman shared:

I was reading what they were saying on flaxseed, going, 'Can you just stop waffling?' Whoever had drafted it didn't want to take a position, but it left you not knowing what the hell you should do!"

In addition to being inundated by the large volume of information, the women were frustrated by the lack of conclusive information, particularly regarding CTs. Another woman commented:

I get scared because you hear soy is bad and you hear soy might not be bad... You think something's good, and then you know next week it's going to be bad so I've just sort of done nothing. I'm doing acupuncture and I find that helps and other than that I'm kind of scared to venture into it. There's so much information. You get overwhelmed. Like flaxseed is supposed to be good for $\mathrm{BrCa}$, but too much can promote $\mathrm{BrCa}$ so you sort of throw up your arms!

The majority of women were also frustrated by their inability to differentiate between credible and non-credible information sources. They struggled to determine the trustworthiness 
of information, particularly sources from the media, the Internet, and for some, even HCPs.

I experienced a growing distrust of the whole system. One person says something, one person says another and [I'm] just not trusting information to the point where I get really anxious going to see a doctor...

\section{CT decision-making experience}

The women had difficulty making definitive treatment decisions, as a consequence of unmet information needs, a perceived lack of decisional support, and inconsistent information about the efficacy and safety of therapy options in managing menopausal symptoms after $\mathrm{BrCa}$. Some of the survivors described feeling "paralyzed" in the decision-making process, fearing that a CT could result in the progression or recurrence of cancer. A woman described her decision-making impasse:

...I'm frozen and I don't know what to do, what not to do, and honestly there are so many professionals and practitioners who you can turn to. But at the end of the day I just find everybody so confusing because nobody gives you the same answers as the next person...

Other survivors described themselves as making the conscious decision to "do nothing" after an independent search for information about CTs. Faced with limited and contradictory evidence on the efficacy and safety, these women were uncomfortable with the degree of uncertainty and potential risk associated with many CTs. Instead, they pursued lifestyle interventions, such as exercise or dietary changes, as a way of coping with their menopausal symptoms. Many of the women expressed hesitancy about using pharmaceutical drugs to manage their symptoms; most preferred to avoid further conventional treatment after such intensive cancer treatment.

Those BrCa survivors who did use CTs to manage their hot flashes and other menopausal symptoms engaged in a complex process of seeking and confirming information about the possible risks and benefits. These women valued not only the advice of HCPs but also the information obtained from other trusted individuals, such as family members. Fellow survivors were seen as especially helpful in providing advice about the timing of CT use, such as "do one thing at a time," and "finish [conventional] treatment first." These women ultimately chose a CT that they could afford, readily incorporate into their lives, and employ over an extended period of time.

Despite the differences among the $\mathrm{BrCa}$ survivors regarding their $\mathrm{CT}$ decision, all of them expressed a need for concise and credible information about CT options to support an informed decision. They wanted to be active participants in the decision-making process and avoid a "paternalistic" relationship with HCPs in which their values and beliefs were not respected.

\section{Discussion}

Our findings highlight the profound impact of menopausal symptoms, particularly hot flashes, on the lives of $\mathrm{BrCa}$ survivors. The women in this study shared stories of how hot flashes and related symptoms disrupted their daily activities, caused significant embarrassment and discomfort, and negatively impacted their quality of life. Because many survivors were hesitant to use HRT due to their BrCa diagnosis and avoided pharmaceutical drugs because of the potential side effects, these women tried a variety of CT options, including NHPs and mind-body therapies, as well as lifestyle interventions. Many of the survivors, however, found the decisionmaking process challenging. Not only was it difficult to obtain information from HCPs about CTs, the information they did receive was often contradictory in nature. Another barrier that hampered BrCa survivors' decision-making was the confusion around which HCP was responsible for informing survivors of the various treatment strategies. In the end, the women expressed the need for concise and credible information about the efficacy and safety of using CTs to managing menopausal symptoms to support them in participating in a shared decision-making process with their HCPs.

Previous research has confirmed the significant effect menopausal symptoms have on women following $\mathrm{BrCa}$ treatment $[2,15]$ as well as the popularity of CTs among BrCa survivors, particularly within the context of menopausal symptom management $[17,18,43]$. Similar to our findings, prior qualitative research has reported BrCa survivors' interest in CTs to arise, in part, from their concerns about the potential side effects of pharmaceutical treatment options [43]. Mao et al. also highlighted the important role that physicians and family members play in $\mathrm{BrCa}$ survivors' decision-making process related to CTs [43]. To our knowledge, however, our study is the first to uncover the confusion experienced by women regarding which physician to consult about their menopausal symptoms (i.e., oncologist versus primary care physician), as well as their frustration with the limited and contradictory information available in conventional care settings related to CTs. The fear expressed by women related to using a CT that could lead to a recurrence of cancer highlights the need for evidence-based information about the safety of CTs in the context of BrCa survivorship. Further, our study adds to the existing literature by including the perspective of HCPs, who struggled to provide recommendations about menopausal treatment options in the absence of established guidelines for $\mathrm{BrCa}$ survivors. The HCPs involved in our study identified the need for a resource that synthesized the latest research on CTs 
to allow them to provide consistent, evidence-based advice to survivors about the efficacy and safety of various therapies in managing menopausal symptoms.

Our study findings reflect a larger issue in the literature regarding the long-term management of cancer survivors and where survivorship care is best located [44]. The lack of national or international clinical guidelines regarding menopausal symptom management in women with $\mathrm{BrCa}$ is a significant gap that requires immediate attention. Rigorous, welldesigned clinical research focused on CTs and menopausal symptom management in $\mathrm{BrCa}$ populations is also needed to address the growing interest by $\mathrm{BrCa}$ survivors in CTs. As this body of clinical research expands, decision support interventions will be required that summarize the latest evidence related to the efficacy and safety of these therapies and translate this knowledge to the bedside [36]. From BrCa survivors' perspective, such interventions must provide clear treatment recommendations to help alleviate their fear and uncertainty and to support their participation in shared decision-making with HCPs.

\section{Implications for CT decision support}

The challenges experienced by $\mathrm{BrCa}$ survivors and HCPs to engage in informed, evidence-based discussions about CT options for menopausal symptom management point to the need for effective and tailored knowledge translation and decision support strategies that can be easily implemented within varied clinical settings. Patient DAs are one strategy that efficiently translates evidence-based health information and support shared decision-making between individuals and their $\mathrm{HCP}$, as well as acknowledging patients' unique beliefs and values [31]. A patient DA would address BrCa survivors' information needs related to CT and menopausal symptom management by concisely summarizing what is currently known and unknown about conventional and complementary treatment options, account for survivors' health and healthcare experiences (e.g., diagnosis, severity of menopausal symptoms, treatment preferences), and be utilized in both oncology and primary care settings.

\section{Limitations}

Although efforts to ensure survivor diversity within the sampling process were undertaken, the composition of a largely Caucasian, well educated, early stage (I and II) BrCa sample limits broad applicability of the study findings. For example, women with later stage disease (>II) may assess risk and make decisions about the use of CTs differently than those with earlier stage disease [45]. Purposeful sampling from two different urban centers, while adding some diversity, does not include perspectives of women living in rural and remote settings, where access to CTs and the influence of sociocultural practices may differentially influence menopause management strategies and CT choices. Patient DAs tailored to women's unique menopause-related CT needs and accounting for their social context may provide an accessible and feasible form of decision support.

\section{Conclusion}

BrCa survivors suffer profoundly from hot flashes and other menopausal symptoms associated with cancer treatment. Faced with limited treatment options, many women consider CTs for relief of their symptoms. Survivors and HCPs, however, lack credible and concise information about the efficacy and safety of CTs. High-quality clinical trials are needed that expand the evidence base regarding the efficacy and safety of CTs in the management of menopausal symptoms following $\mathrm{BrCa}$ treatment. Patient DAs are one decision support strategy that may help synthesize and translate research on CTs as well as empower BrCa survivors and HCPs to engage in shared decision-making about the full range of therapeutic options for managing menopausal symptoms.

Acknowledgments This study was funded by the Canadian Cancer Society (grant no. 020658). Dr. Balneaves was funded by a Canadian Institutes of Health Research (CIHR) New Investigator award (20082013), and Ms. Lambert was a recipient of a CIHR Psychosocial Oncology Research Training Fellowship.

Open Access This article is distributed under the terms of the Creative Commons Attribution-NonCommercial 4.0 International License (http:/ creativecommons.org/licenses/by-nc/4.0/), which permits any noncommercial use, distribution, and reproduction in any medium, provided you give appropriate credit to the original author(s) and the source, provide a link to the Creative Commons license, and indicate if changes were made.

\section{References}

1. Antoine C, Liebens F, Carly B, Pastijn A, Rozenberg S (2007) Safety of alternative treatments for menopausal symptoms after breast cancer: a qualitative systematic review. Climacteric 10:2326

2. Gupta P, Sturdee DW, Palin SL, Majumder K, Fear R, Marshall T, Paterson I (2006) Menopausal symptoms in women treated for breast cancer: the prevalence and severity of symptoms and their perceived effects on quality of life. Climacteric 9:49-58

3. Leining MG, Gelber S, Rosenberg R, Przypyszny M, Winer EP, Partridge AH (2006) Menopausal-type symptoms in young breast cancer survivors. Ann Oncol 17:1777

4. Marino JL, Saunders CM, Emery LI, Green H, Doherty DA, Hickey M (2014) Nature and severity of menopausal symptoms and their impact on quality of life and sexual function in cancer survivors compared with women without a cancer history. Menopause 21:267-274

5. Crandall C, Petersen L, Ganz PA, Greendale GA (2004) Association of breast cancer and its therapy with menopauserelated symptoms. Menopause 11:519-530 
6. Harris PF, Remington PL, Trentham-Dietz A, Allen CI, Newcomb PA (2002) Prevalence and treatment of menopausal symptoms among breast cancer survivors. J Pain Symptom Manag 23:501-509

7. Dailey RK, Neale AV, Northrup J, West P, Schwartz KL (2003) Herbal product use and menopause symptom relief in primary care patients: a MetroNet study. J Women's Health 12:633-641

8. Beral V, Banks E, Reeves G, Bull D (2003) Breast cancer and hormone-replacement therapy: the Million Women Study. Lancet 362:1330-1331

9. Fahlen M, Fornander T, Johansson H, Johansson U, Rutqvist LE, Wilking N, von Schoultz E (2013) Hormone replacement therapy after breast cancer: 10 year follow up of the Stockholm randomised trial. Eur J Cancer 49:52-59

10. Daley A, Stokes-Lampard H, Thomas A, MacArthur C (2014) Exercise for vasomotor menopausal symptoms. Cochrane Database Syst Rev 11:CD006108

11. Innes KE, Selfe TK, Vishnu A (2010) Mind-body therapies for menopausal symptoms: a systematic review. Maturitas 66:135-149

12. Morrow PK, Mattair DN, Hortobagyi GN (2011) Hot flashes: a review of pathophysiology and treatment modalities. Oncologist $16: 1658-1664$

13. Armitage GD, Suter E, Verhoef MJ, Bockmuehl C, Bobey M (2007) Women's needs for CAM information to manage menopausal symptoms. Climacteric 10:215-224

14. Daley A, MacArthur C, McManus R, Stokes-Lampard H, Wilson S, Roalfe A, Mutrie N (2006) Factors associated with the use of complementary medicine and non-pharmacological interventions in symptomatic menopausal women. Climacteric 9:336

15. Hunter MS, Grunfeld EA, Mittal S, Sikka P, Ramirez AJ, Fentiman I, Hamen H (2004) Menopausal symptoms in women with breast cancer: prevalence and treatment preferences. Psychooncology 13: 769-778

16. van der Sluijs CP, Bensoussan A, Liyanage L, Shah S (2007) Women's health during mid-life survey: the use of complementary and alternative medicine by symptomatic women transitioning through menopause in Sydney. Menopause 14:397

17. Buettner C, Kroenke CH, Phillips RS, Davis RB, Eisenberg DM, Holmes MD (2006) Correlates of use of different types of complementary and alternative medicine by breast cancer survivors in the nurses' health study. Breast Cancer Res Treat 100:219

18. Matthews AK, Sellergren SA, Huo D, List M, Fleming G (2007) Complementary and alternative medicine use among breast cancer survivors. J Altern Complement Med 13:555-562

19. Suter E, Verhoef MJ, Bockmuehl C, Forest N, Bobey M, Armitage GD (2007) Inquiring minds: women's approaches to evaluating complementary and alternative therapies for menopausal symptoms. Can Fam Physician 53:84-90

20. Pilkington K, Gamst A, Liu I, Ostermann T, Pinto D, Richardon J (2011) The International Collaboration on Complementary Therapy Resources (ICCR): working together to improve online CAM information. J Altern Complement Med 17:647-653

21. Légaré F, Stacey D, Dodin S, O'Connor A, Richer M, Griffiths F, LeBlanc A, Rousseau JL, Tapp S (2007) Women's decision making about the use of natural health products at menopause: a needs assessment and patient decision aid. J Altern Complement Med 13:741-749

22. Nelson HD, Vesco KK, Haney E, Fu R, Nedrow A, Miller J, Nicolaidis C, Walker M, Humphrey L (2006) Nonhormonal therapies for menopausal hot flashes: systematic review and meta-analysis. JAMA 295:2057-2071

23. Chen MN, Lin CC, Liu CF (2015) Efficacy of phytoestrogens for menopausal symptoms: a meta-analysis and systematic review. Climacteric 18:260-269

24. Chiu HY, Pan CH, Shyu YK, Han BC, Tsai PS (2015) Effects of acupuncture on menopause-related symptoms and quality of life in women in natural menopause: a meta-analysis of randomized controlled trials. Menopause 22:234-244

25. Bokmand S, Flyger H (2013) Acupuncture relieves menopausal discomfort in breast cancer patients: a prospective, double blinded, randomized study. Breast 22:320-323

26. Rostock M, Fischer J, Mumm A, Stammwitz U, Saller R, Bartsch HH (2011) Black cohosh (Cimicifuga racemosa) in tamoxifentreated breast cancer patients with climacteric complaints - a prospective observational study. Gynecol Endocrinol 27:844-848

27. Walker EM, Rodriguez AI, Kohn B, Ball RM, Pegg J, Pocock JR, Nunez R, Peterson E, Jakary S, Levine RA (2010) Acupuncture versus venlafaxine for the management of vasomotor symptoms in patients with hormone receptor-positive breast cancer: a randomized controlled trial. J Clin Oncol 28:634-640

28. Balneaves LG, Truant TL, Kelly M, Verhoef MJ, Davison BJ (2007) Bridging the gap: decision-making processes of women with breast cancer using complementary and alternative medicine (CAM). Support Care Cancer 15:973-983

29. Elwyn G, O'Connor A, Stacey D, Volk R, Edwards A, Coulter A, Thomson R, Barratt A, Barry M, Bernstein S (2006) Developing a quality criteria framework for patient decision aids: online international Delphi consensus process. Br Med J 333:417

30. Légaré F, Dodin S, Stacey D, LeBlanc A, Tapp S (2008) Patient decision aid on natural health products for menopausal symptoms: randomized controlled trial. Menopause Int 14:105-110

31. Stacey D, Legare F, Col NF, Bennett CL, Barry MJ, Eden KB, Holmes-Rovner M, Llewellyn-Thomas H, Lyddiatt A, Thomson R, Trevena L, Wu JH (2014) Decision aids for people facing health treatment or screening decisions. Cochrane Database Syst Rev 1: CD001431

32. Woolf SH, Chan ECY, Harris R, Sheridan SL, Braddock CH III, Kaplan RM, Krist A, O'Connor AM, Tunis S (2005) Promoting informed choice: transforming health care to dispense knowledge for decision making. Ann Intern Med 143:293-300

33. Légaré F, Ratte S, Stacey D, Kryworuchko J, Gravel K, Graham ID, Turcotte $S$ (2014) Interventions for improving the adoption of shared decision making by healthcare professionals. Cochrane Database Syst Rev 9:CD006732

34. O'Connor AM, Tugwell P, Wells GA, Elmslie T, Jolly E, Hollingworth G, McPherson R, Bunn H, Graham I, Drake E (1998) A decision aid for women considering hormone therapy after menopause: decision support framework and evaluation. Patient Educ Couns 33:267-367 279

35. Sandelowski M (2000) Whatever happened to qualitative description? Res Nurs Health 23:334-340

36. Balneaves LG, Truant TL, Verhoef MJ, Ross B, Porcino AJ, Wong M, Brazier AS (2012) The Complementary Medicine Education and Outcomes (CAMEO) program: a foundation for patient and health professional education and decision support programs. Patient Educ Couns 89:461-466

37. de Lemos ML (2001) Effects of soy phytoestrogens genistein and daidzein on breast cancer growth. Ann Pharmacother 35:1118-1121

38. Walji R, Boon H, Guns E, Oneschuk D, Younus J (2007) Black cohosh (Cimicifuga racemosa [L.] Nutt.): safety and efficacy for cancer patients. Support Care Cancer 15:913-921

39. Balneaves LG, Bottorff JL, Hislop TG, Herbert C (2006) Levels of commitment: exploring complementary therapy use by women with breast cancer. J Altern Complement Med 12:459-466

40. Standish LJ, Greene K, Greenlee H, Kim JG, Grosshans C (2002) Complementary and alternative medical treatment of breast cancer: a survey of licensed North American naturopathic physicians. Altern Ther Health Med 8(74-6):78-81

41. Jacobsen MJ, O'Connor A (2006) Population needs assessment: a workbook for assessing patients' and practitioners' decision making needs. http://decisionaid.ohri.ca/docs/implement/Population Needs.pdf. Accessed 11/15 2007. 
42. Schneider HP, Heinemann LA, Rosemeier HP, Potthoff P, Behre HM (2000) The Menopause Rating Scale (MRS): reliability of scores of menopausal complaints. Climacteric 3:59-64

43. Mao JJ, Leed R, Bowman MA, Desai K, Bramble M, Armstrong K, Barg F (2012) Acupuncture for hot flashes: decision making by breast cancer survivors. J Am Board Fam Med 25:323-332
44. Rowland JH (2011) Cancer survivorship plans: a paradigm shift in the delivery of quality cancer care. In: Feuerstein M, Ganz PA (eds) Health services for cancer survivors. Springer, New York, pp. 169-185

45. Truant TL, Porcino AJ, Ross BC, Wong ME, Hilario CT (2013) Complementary and alternative medicine (CAM) use in advanced cancer: a systematic review. J Support Oncol 11:105-113 